This item was submitted to Loughborough's Research Repository by the author.

Items in Figshare are protected by copyright, with all rights reserved, unless otherwise indicated.

\title{
Scalable deposition of high-efficiency perovskite solar cells by spray-coating
}

PLEASE CITE THE PUBLISHED VERSION

https://doi.org/10.1021/acsaem.8b00328

PUBLISHER

(c) American Chemical Society

VERSION

VoR (Version of Record)

\section{PUBLISHER STATEMENT}

This work is made available according to the conditions of the Creative Commons Attribution 4.0 International (CC BY 4.0) licence. Full details of this licence are available at: http://creativecommons.org/licenses/ by/4.0/

\section{LICENCE}

CC BY 4.0

\section{REPOSITORY RECORD}

Ulicna, Sona, Benjia Dou, Dong H. Kim, Kai Zhu, Michael Walls, Jake Bowers, and Maikel F.A.M. van Hest. 2018. "Scalable Deposition of High-efficiency Perovskite Solar Cells by Spray-coating". Loughborough University. https://hdl.handle.net/2134/33197. 


\section{Scalable Deposition of High-Efficiency Perovskite Solar Cells by Spray-Coating}

Soňa Uličná,*,†® Benjia Dou, ${ }^{\ddagger, \S}$ Dong Hoe Kim, ${ }^{\ddagger}$ Kai Zhu, ${ }^{\ddagger}{ }^{\ddagger}$ John M. Walls, ${ }^{\dagger}$ Jake W. Bowers, ${ }^{\dagger}$ and Maikel F. A. M. van Hest*,

${ }^{\dagger}$ Centre for Renewable Energy Systems Technology, Wolfson School of Mechanical, Electrical and Manufacturing Engineering, Loughborough University, Loughborough, Leicestershire LE11 3TU, United Kingdom

${ }^{\ddagger}$ National Renewable Energy Laboratory, Golden, Colorado 80401, United States

${ }^{\S}$ Department of Electrical, Computer and Energy Engineering, University of Colorado Boulder, Boulder, Colorado 80309, United States

Supporting Information

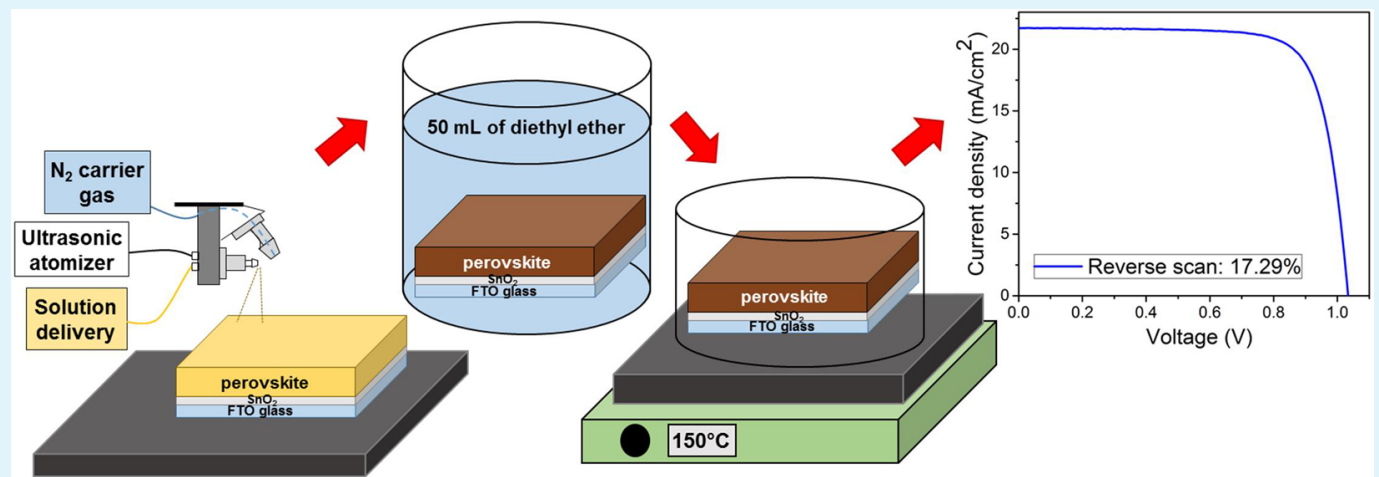

ABSTRACT: Spray-deposition is a low-cost, roll-to-roll compatible technique that could potentially replace spin-coating for the deposition of highly efficient perovskite solar cells. Here, perovskite active layers were fabricated in air using an ultrasonic spray system and compared with equivalent spin-coated films. A chlorine-containing perovskite ink with a wide processing window coupled with an antisolvent extraction resulted in perovskite films with relatively rougher surfaces than those spin-coated. A power conversion efficiency (PCE) of $17.3 \%$ was achieved with an average of $16.3 \%$ from 24 devices. Despite observing differences in film roughness and structure, the performance of sprayed perovskite solar cells was comparable to that of the spincoated cells processed in an inert atmosphere, showing the versatility of perovskite processing.

KEYWORDS: perovskite solar cell, solution processing, ultrasonic spraying, scalable atmospheric deposition, wide processing window ink

$\mathrm{P}$ erovskite solar cells have recently attracted enormous attention. Perovskites as an absorber material possess exceptional optoelectronic properties and versatility due to an extensive variety of elemental combinations incorporated into one of the three lattice sites of the general $\mathrm{ABX}_{3}$ perovskite structure. ${ }^{1}$ Another advantage of perovskite solar cells is that it uses relatively inexpensive materials. The processing is vacuumfree and at low-temperature from solution. The power conversion efficiency (PCE) of organic-inorganic metal halides perovskite solar cells has increased to an impressive $22.7 \%$ in only a few years. ${ }^{2}$ However, to date, the most efficient devices have been fabricated using spin-coating which is inefficient in its use of materials and does not lend itself to industrial scaling.

Spray-coating is a relatively simple, low-cost atmospheric deposition technique which has high material utilizationefficiency and high throughput. It is also an attractive technique from a manufacturing perspective. Different deposition methods often result in different nucleation and crystal growth mechanisms. Therefore, film morphology and performance is not easily transferable from one deposition method to another. ${ }^{3,4}$ An additional challenge is the application of the antisolvent commonly used during spin-coating to form a highly uniform and smooth perovskite thin film. ${ }^{5}$ An antisolvent, typically chlorobenzene or toluene, is added during spin-coating within seconds, which would be a challenge to apply in a scalable technique. Several groups using spraycoating as a deposition method have overcome the antisolvent issue by spraying on substrates at temperatures higher than room temperature. The highest-efficiency perovskite solar cell (18.3\%) fabricated using spray-coating was deposited at a substrate temperature of $120{ }^{\circ} \mathrm{C} .{ }^{6}$ Recently Zhu and van Hest et al. developed a versatile perovskite ink with a wide processing window suitable for spin-coating as well as blade-

Received: March 3, 2018

Accepted: $\quad$ May 4, 2018

Published: May 4, 2018 
coating. ${ }^{4}$ The solvent combination of $N, N$-dimethylformamide (DMF) and $N$-methyl-2-pyrroilidinone (NMP) with a carefully optimized ratio was shown to extend the precursor film processing time (or antisolvent application time) from seconds to minutes.

In the present work, we demonstrate an application of the chlorine $(\mathrm{Cl})$-containing methylamine lead iodide $\left(\mathrm{MAPbI}_{3}\right)$ ink with a wide processing window for spray-coating perovskite solar cells in ambient conditions. By this means, we demonstrate that this ink has an even better versatility and transferability and can be used in a scalable deposition method such as spraying. The optimization process of the spraying conditions is described. The performance of a spray-coated device is compared to that of a reference spin-coated cell.

\section{RESULTS AND DISCUSSION}

Initially, an optimization of the spraying conditions was carried out to obtain a pinhole-free, semitransparent film with optimum thickness and low surface roughness. During spraying, a balance was established between the supply of precursor solution (solution flow rate) and the evaporation of solvents during the drying of the wet film (solvent characteristics). The NMP in the solvent mixture substitutes for the commonly used dimethyl sulfoxide (DMSO). This has the advantage of a high boiling point $\left(204{ }^{\circ} \mathrm{C}\right)$ and low vapor pressure $(0.038 \mathrm{kPa}$ at 20 $\left.{ }^{\circ} \mathrm{C}\right)$. Therefore, the use of a mixture with fast-evaporating DMF (boiling point, $154{ }^{\circ} \mathrm{C}$; vapor pressure, $0.36 \mathrm{kPa}$ at $20{ }^{\circ} \mathrm{C}$ ) extends the duration of the wet-stage. This is important in spraying as a wet film is required at the end of the deposition process which can persist longer than with spin-coating, when large-area substrates are to be coated. In the following antisolvent bath stage, the excess polar precursor solvent from the wet film is effectively extracted with the nonpolar diethyl ether allowing for a rapid crystallization and formation of a uniform, smooth, and semitransparent perovskite thin film. This concept is also known as solvent-solvent extraction used for room-temperature crystallization of perovskite thin films. ${ }^{7,8}$ In this postdeposition solvent removal approach, the lowtemperature bath promotes a high nuclei density for better film coverage, and the subsequent anneal at $150{ }^{\circ} \mathrm{C}$ results in grain coarsening. By this means, the undesirable competition between nucleation and coarsening, also referred to as Ostwald ripening, is avoided. ${ }^{9}$ However, if the delay between the precursor film being deposited and the antisolvent bath is too long, the film will rapidly change its appearance from clear to hazy and consequently have a negative effect on the device performance. Moreover, using a highly viscous NMP (1.67 mPa s) in the final $9 / 8 \mathrm{v} / \mathrm{v} \mathrm{NMP} / \mathrm{DMF}$ mixture resulted in a perovskite ink with a suitable viscosity for spraying for a wide range of flow rates and good surface wettability.

Optimum thickness is one of the critical parameters for highefficiency perovskite solar cells. If the perovskite film is too thin, not all photons will be absorbed resulting in reduced photocurrents. However, if the perovskite film is too thick, the efficiency of the charge carrier extraction is reduced and recombination becomes more severe, again resulting in reduced photocurrents. A thickness in the range $300-600 \mathrm{~nm}$ is commonly used for highly efficient devices. ${ }^{10}$ Figure 1 shows the evolution of the spray-coated film thickness and roughness as a function of the solution flow rate and automated stage speed. Figure S1 of the Supporting Information displays a roughness profile of a perovskite film typically obtained from (a)

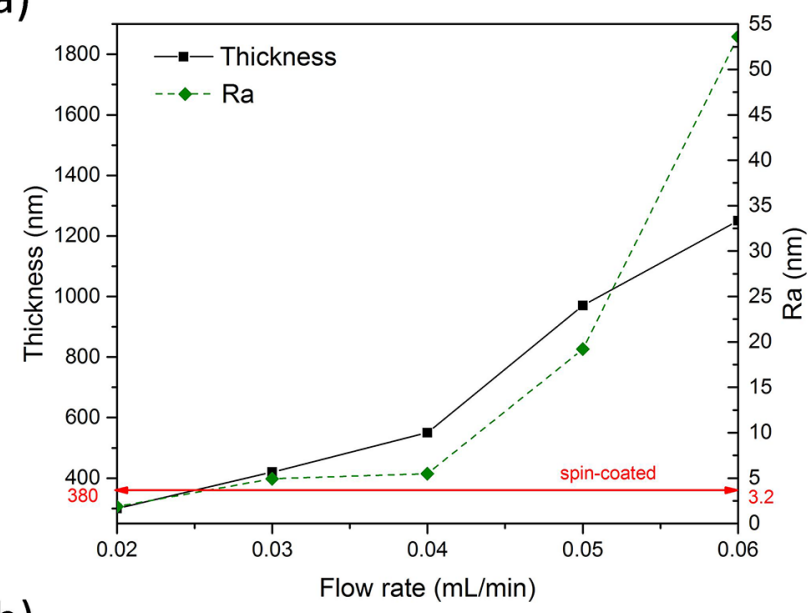

(b)

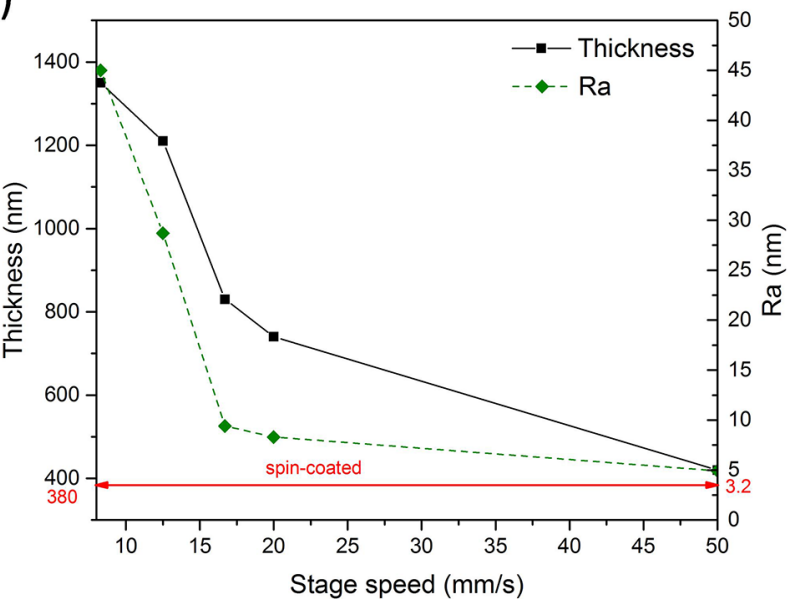

Figure 1. Perovskite film thickness and roughness at varied solution flow rate (a) and stage speed (b).

average of 9000 data points over $500 \mu \mathrm{m}$ measured using a DekTak Stylus Profiler.

The precursor solution flow rate was varied from 0.02 to 0.06 $\mathrm{mL} / \mathrm{min}$ using a $50 \mathrm{~mm} / \mathrm{s}$ stage speed. As expected, the film thickness increased with the increase in flow rate, but the film roughness (Ra: arithmetic average deviation) also increased dramatically with flows over $0.04 \mathrm{~mL} / \mathrm{min}$. The speeds were varied from 8.3 to $50 \mathrm{~mm} / \mathrm{s}$ with the flow rate kept constant at $0.03 \mathrm{~mL} / \mathrm{min}$. The thickness decreased from over $1 \mu \mathrm{m}$ to approximately $420 \mathrm{~nm}$ at the highest stage speed employed (50 $\mathrm{mm} / \mathrm{s}$ ). Along with the thickness, the surface roughness decreased, reaching $\approx 5.0 \mathrm{~nm}$ for the $0.03 \mathrm{~mL} / \mathrm{min}$ and 50 $\mathrm{mm} / \mathrm{s}$ sample. In comparison, a spin-coated perovskite film was approximately $380 \mathrm{~nm}$ thick with a Ra roughness coefficient of $\approx 3.2 \mathrm{~nm}$.

Figure 2 shows bright-field microscope images and photographs of the spin- and spray-coated films deposited on glass substrates. Square inch sized glass substrates were used in order to facilitate and accelerate the spraying optimization process and allow for a direct comparison with a small-area spin-coating method. However, substrates of a larger area can be coated using the spraying setup described in the Supporting Information. Pinhole-free films with full substrate coverage are obtained by ultrasonic spraying using a $0.03 \mathrm{~mL} / \mathrm{min}$ solution flow rate and $50 \mathrm{~mm} / \mathrm{s}$ stage speed. The microscope images confirm that the sprayed films have higher surface 


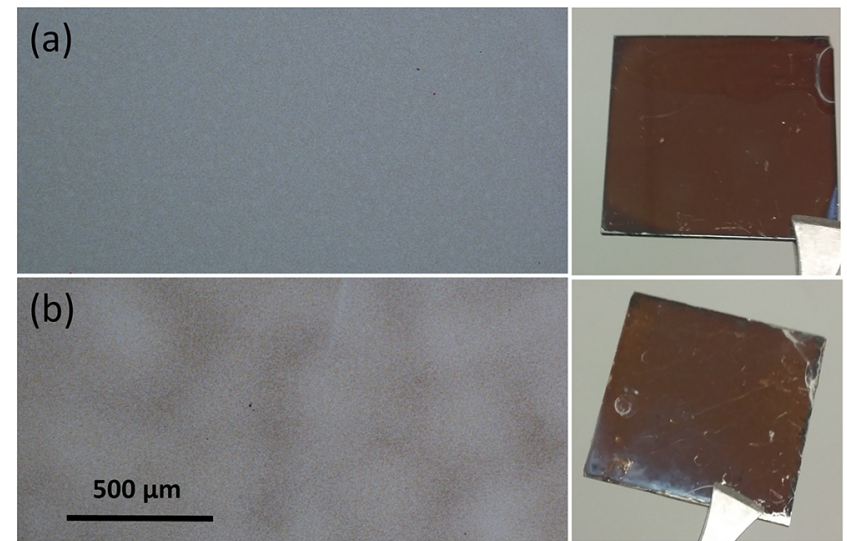

Figure 2. Bright-field optical microscope images and photographs of the as-deposited perovskite films using the spin-coating (a) and ultrasonic spraying (b) method.

roughness than those spin-coated. Nonetheless, a difference in the film morphology is not expected as the coating method only deposits the wet film. Drying of the film and subsequent crystallization occur during the antisolvent bath; therefore, after the deposition the films are equal (independent of the deposition method) and as such the final film is equal as well. Furthermore, the same film morphology after using bladecoating and spin-coating has been evidenced in our previous study using the same solution chemistry. ${ }^{4}$

Figure $3 a$ compares the absorption spectra of the films deposited by spin- and spray-coating. The absorbance of the sprayed film is slightly higher than the spin-coated film. This is likely due to the greater thickness and roughness of the sprayed films. Other processes such as crystallization changes could be happening, although this is unlikely, considering the similar PV performance obtained from both of these devices.

Figure $3 \mathrm{~b}$ compares the XRD patterns for the spin- and spray-coated films. The main perovskite XRD peaks (e.g., $2 \theta$ $\sim 14.1^{\circ}$ and $\sim 28.4^{\circ}$ ) are present with strong intensity. There is a small shift of these peaks toward higher $2 \theta$ angles $\left(14.25^{\circ}\right.$ and $28.55^{\circ}$ ) for the sprayed film. This can originate from the formation of intermediate states or stress in different processing methods. ${ }^{4}$ The XRD peak at $28.4^{\circ}$ is a double peak caused by phase impurities, such as the coexistence of cubic and tetragonal phases of the perovskite material.

The device PCE statistics for perovskite solar cells fabricated with spin- and spray-coated active layers extracted from $J-V$ curves in forward and reverse scan of 24 devices from each coating approach are shown in Figure 4a. The PCEs from the reverse scan of samples made using spray-coating have similar values but a much tighter distribution when compared with those of the spin-coated devices, suggesting more consistent processing with spray-coating. In both processing methods, severe hysteresis is observed. This can be attributed to the conduction band misalignment between $\mathrm{SnO}_{2}$ and $\mathrm{MAPbI}_{3}{ }^{11}$ Data might suggest that the forward scan PCE is slightly lower for the sprayed devices compared to the spin-coated devices. Hysteresis in perovskite solar cells is generally attributed to the property of the perovskite and the interface between the charge collection layers and the perovskite. ${ }^{12}$ In sprayed perovskite cells, the interfaces with the spin-coated $\mathrm{SnO}_{2}$ as electron transport layer (ETL) and spin-coated spiro-OMeTAD as hole transport layer (HTL) are of lower quality due to the higher surface roughness of the perovskite. Therefore, more (a)

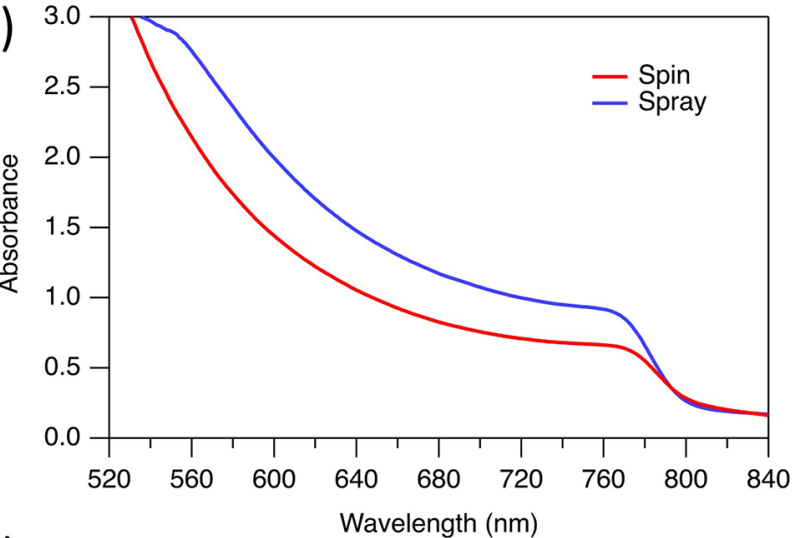

(b)
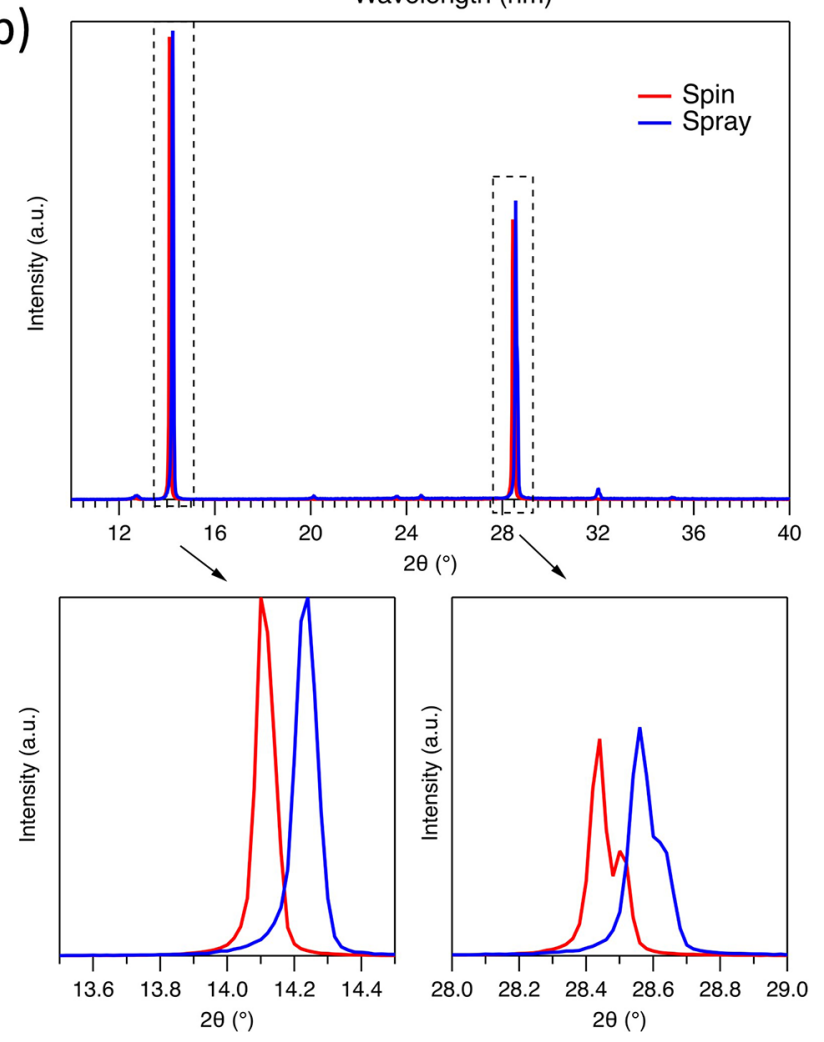

Figure 3. Absorption spectra (a) and XRD patterns (b). Comparison between spin- and spray-coated perovskite films.

pronounced hysteresis is expected from these films. There is potential to reduce the hysteresis and improve the PCE by including a $[6,6]$-phenyl-C61-butyric acid methyl ester (PCBM) layer between the ETL and perovskite films.,13

Table 1 summarizes the average and standard deviation of the PV performance indicators of 24 devices extracted from reversely scanned $J-V$ curves for each deposition technique. Table 1 confirms that, in reverse bias, the PCE of sprayed devices is identical to the PCE of the spin-coated devices as shown in Figure 4a. The same PCE was obtained even though the spin-coating was performed in an inert atmosphere of a $\mathrm{N}_{2}$ glovebox and spraying was performed in ambient air. The different deposition environment does not seem to affect the chemistry used. Sprayed devices demonstrate higher opencircuit voltage $\left(V_{\mathrm{OC}}\right)$ and short-circuit current $\left(J_{\mathrm{SC}}\right)$, but have a lower fill factors (FF) than spin-coated devices. The differences in the PV parameters are due to different film formation mechanisms occurring when the perovskite layers were 

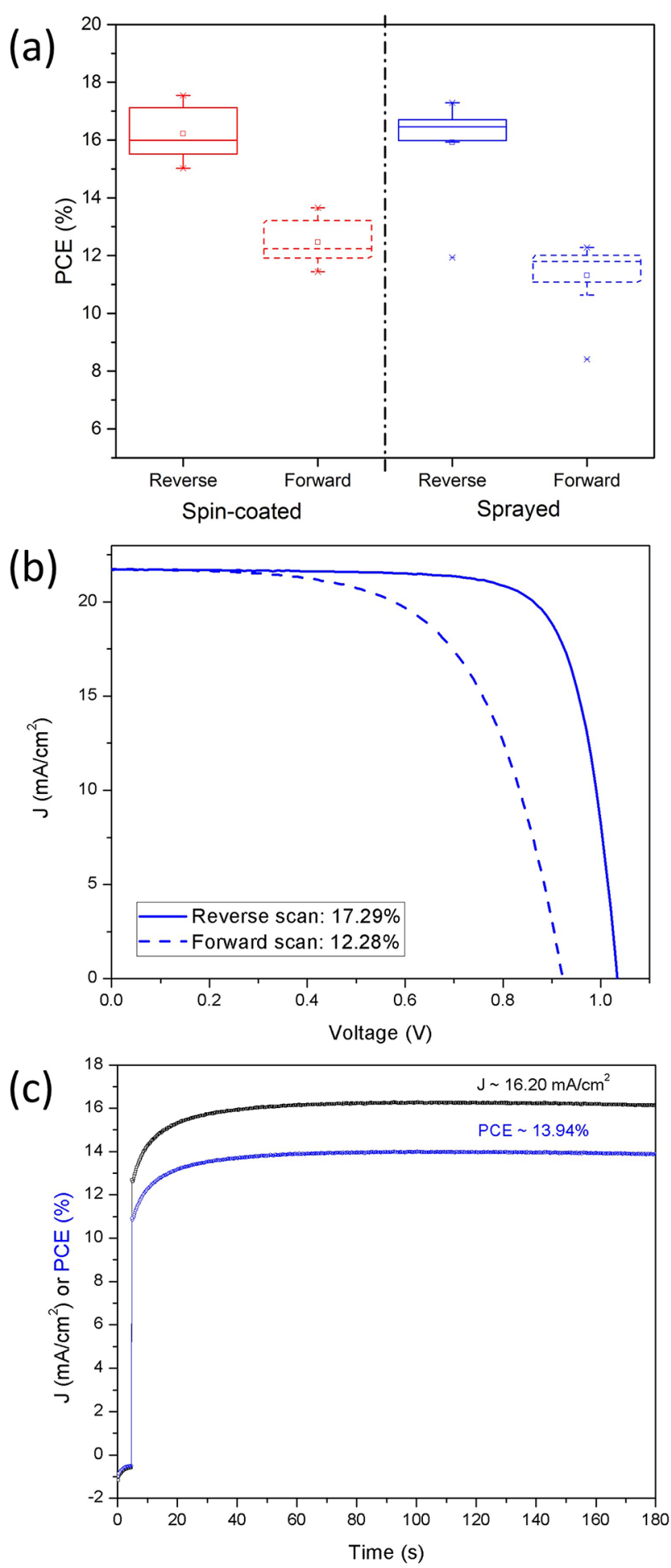

Figure 4. Comparison of device PCE distribution using spin- and spray-coated perovskite solar cells measured in reverse and forward bias (a). $J-V$ curves with both forward and reverse scans (b) and stabilized power output near maximum power point (c) for the champion sprayed perovskite device. deposited using the different methods. Except for the crystallization process (diethyl ether bathing), the initial wet film preparation was different for the two deposition methods. While in spin-coating the film formation is driven by the centrifugal force of spinning, the sprayed films are formed by coalescing of solution droplets that reached the substrate. A higher film thickness and roughness could explain the higher $J_{S C}$ in the sprayed film. Lower FF in the sprayed devices can be attributed to a poorer interface between $\mathrm{SnO}_{2}$ and perovskite causing a higher resistance with the contact layers.

Figure $4 \mathrm{~b}, \mathrm{c}$ shows the $J-V$ curve and the stabilized power output (SPO) monitored over time near the maximum power point of the champion device obtained with a sprayed perovskite active layer. The voltage was held constant at 0.86 $\mathrm{V}$ for $180 \mathrm{~s}$ to measure the SPO. $J-V$ hysteretic behavior and lower SPO are often reported in the literature for $\mathrm{SnO}_{2} /$ $\mathrm{MAPbI}_{3}$ perovskite solar cells. ${ }^{14,15}$ Table 2 summarizes the PV

Table 2. PV Parameters of the Champion Cell Fabricated Using Spin- and Spray-Coating Deposition Techniques

\begin{tabular}{lcccc} 
& $J_{\mathrm{SC}}\left(\mathrm{mA} / \mathrm{cm}^{2}\right)$ & $V_{\mathrm{OC}}(\mathrm{V})$ & FF & PCE $(\%)$ \\
sprayed & 21.70 & 1.033 & 77.0 & 17.29 \\
spin-coated & 20.80 & 1.058 & 79.6 & 17.54 \\
\hline
\end{tabular}

parameters of the champion cells for both deposition techniques extracted from the reverse scan. Similarly, in the work presented by Zhu and van Hest et al. using the same ink formulation for blade-coating and spin-coating, an identical film morphology and device performance was achieved using both deposition methods. ${ }^{4}$ After careful optimization of the $\mathrm{MACl}$ content (30 wt \%), Zhu and van Hest et al. have reported a PCE of $16.77 \%$, which is similar to the PCE obtained in this study (17.29\% PCE). The performance and hysteresis can be further improved by modifying the ETL as Zhu and van Hest et al. reported where modification of $\mathrm{TiO}_{2}$ with $\mathrm{PCBM}$ increased the PCE to $19.06 \%$ with less than $3 \%$ hysteresis. $^{4}$

\section{CONCLUSIONS}

Perovskite films suitable for use in thin-film solar cells were successfully deposited using a low-cost large-area ultrasonic spraying technique in ambient conditions. A perovskite ink with a wide processing window for the application of an antisolvent and significantly reduced annealing time was chosen as a precursor solution. After optimizing the spraying conditions, the sprayed perovskite solar cells achieved a PCE of $17.29 \%$. Despite the rougher surface morphology and a small shift in the XRD peaks of sprayed perovskite films, the resulting device performance was comparable to the reference cells fabricated using a spin-coated perovskite precursor. This similar performance achieved with different processing methods indicates the versatility of the perovskite thin-film processing and could potentially bridge the gap between the PCEs of laboratory-scale and large-area perovskite deposition methods. ${ }^{16}$

Table 1. Average Values for PV Parameters of Spin- and Spray-Coated Devices Measured in Reverse Scan ${ }^{a}$

$\begin{array}{lccc} & J_{\mathrm{SC}}\left(\mathrm{mA} / \mathrm{cm}^{2}\right) & V_{\mathrm{OC}}(\mathrm{V}) & \text { PCE }(\%) \\ \text { sprayed } & 21.20 \pm 0.46 & 1.021 \pm 0.012 & 0.750 \pm 0.021 \\ \text { spin-coated } & 20.87 \pm 0.20 & 0.989 \pm 0.042 & 0.784 \pm 0.009\end{array}$

$a_{24}$ cells for each deposition method were tested. 


\section{ASSOCIATED CONTENT}

\section{S Supporting Information}

The Supporting Information is available free of charge on the ACS Publications website at DOI: 10.1021/acsaem.8b00328.

Experimental details on the perovskite film and solar cell preparation and characterization (PDF)

\section{AUTHOR INFORMATION}

\section{Corresponding Authors}

*E-mail: s.ulicna@lboro.ac.uk. Phone: +44 (0)1509 228263.

*E-mail: Maikel.van.Hest@nrel.gov. Phone: +1 3033846651.

Fax: +13033846430.

ORCID ${ }^{\circ}$

Soňa Uličná: 0000-0001-5287-7179

Benjia Dou: 0000-0001-6038-5561

Kai Zhu: 0000-0003-0908-3909

Notes

The authors declare no competing financial interest.

\section{ACKNOWLEDGMENTS}

We acknowledge the EPSRC Supergen SuperSolar Hub (EP/ J017361/1) as well as a grant no. EP/N026438/1 for funding a 3 month secondment for S.U. at the National Renewable Energy Laboratory in Colorado. This research is based upon work supported in part by the Solar Energy Research Institute for India and the U.S. (SERIIUS) funded jointly by the U.S. Department of Energy subcontract DE AC36-08G028308 (Office of Science, Office of Basic Energy Sciences, and Energy Efficiency and Renewable Energy, Solar Energy Technology Program, with support from the Office of International Affairs) and the Government of India subcontract IUSSTF/JCERDCSERIIUS/2012 dated 22nd Nov. 2012.

\section{REFERENCES}

(1) Manser, J. S.; Saidaminov, M. I.; Christians, J. A.; Bakr, O. M.; Kamat, P. V. Making and Breaking of Lead Halide Perovskites. Acc. Chem. Res. 2016, 49, 330-338.

(2) https://www.nrel.gov/pv/assets/images/efficiency-chart.png (accessed 02/13/2018).

(3) Barrows, A. T.; Pearson, A. J.; Kwak, C. K.; Dunbar, A. D. F.; Buckley, A. R.; Lidzey, D. G. Efficient Planar Heterojunction MixedHalide Perovskite Solar Cells Deposited via Spray-Deposition. Energy Environ. Sci. 2014, 7, 2944-2950.

(4) Yang, M.; Li, Z.; Reese, M. O.; Reid, O. G.; Kim, D. H.; Siol, S.; Klein, T. R.; Yan, Y.; Berry, J. J.; van Hest, M. F. A. M.; Zhu, K. Perovskite Ink with Wide Processing Window for Scalable HighEfficiency Solar Cells. Nature Energy 2017, 2, 17038.

(5) Jeon, N. Y.; Noh, J. H.; Kim, Y. C.; Yang, W. S.; Ryu, S.; Seok, S. I. Solvent Engineering for High-performance Inorganic-Organic Hybrid Perovskite Solar Cells. Nat. Mater. 2014, 13, 897-903.

(6) Heo, J. H.; Lee, M. H.; Jang, M. H.; Im, S. H. Highly Efficient $\mathrm{CH}_{3} \mathrm{NH}_{3} \mathrm{PbI}_{3-\mathrm{x}} \mathrm{Cl}_{\mathrm{x}}$ Mixed Halide Perovskite Solar Cells Prepared by Re-dissolution and Rrystal Grain Growth via Spray Coating. J. Mater. Chem. A 2016, 4, 17636-17642.

(7) Zhou, Y.; Yang, M.; Wu, W.; Vasiliev, A. L.; Zhu, K.; Padture, N. P. Room-temperature crystallization of hybrid-perovskite thin films via solvent-solvent extraction for high-performance solar cells. J. Mater. Chem. A 2015, 3, 8178-8184.

(8) Zhou, Y.; Yang, M.; Game, O. S.; Wu, W.; Kwun, J.; Strauss, M. A.; Yan, Y.; Huang, J.; Zhu, K.; Padture, N. P. Manipulating Crystallization of Organolead Mixed-Halide Thin Films in Antisolvent Baths for Wide-Bandgap Perovskite Solar Cells. ACS Appl. Mater. Interfaces 2016, 8, 2232-2237.
(9) Zhou, Y.; Game, O. S.; Pang, S.; Padture, N. P. Microstructures of Organometal Trihalide Perovskites for Solar Cells: Their Evolution from Solutions and Characterization. J. Phys. Chem. Lett. 2015, 6, 4827-4839.

(10) Lin, Q.; Armin, A.; Nagiri, R. C. R.; Burn, P. L.; Meredith, P. Electro-Optics of Perovskite Solar Cells. Nat. Photonics 2015, 9, 106112.

(11) Correa Baena, J. P.; Steier, L.; Tress, W.; Saliba, M.; Neutzner, S.; Matsui, T.; Giordano, F.; Jacobsson, T. J.; Srimath Kandada, A. R.; Zakeeruddin, S. M.; Petrozza, A.; Abate, A.; Nazeeruddin, M. K.; Gratzel, M.; Hagfeldt, A. Highly Efficient Planar Perovskite Solar Cells Through Band Alignment Engineering. Energy Environ. Sci. 2015, 8, 2928-2934.

(12) Snaith, H. J.; Abate, A.; Ball, J. M.; Eperon, G. E.; Leijtens, T.; Noel, N. K.; Stranks, S. D.; Wang, J. T.-W.; Wojciechowski, K.; Zhang, W. Anomalous Hysteresis in Perovskite Solar Cells. J. Phys. Chem. Lett. 2014, 5, 1511-1515.

(13) Ke, W.; Zhao, D.; Xiao, C.; Wang, C.; Cimaroli, A. J.; Grice, C. R.; Yang, M.; Li, Z.; Jiang, C.-S.; Al-Jassim, M.; Zhu, K.; Kanatzidis, M. G.; Fang, G.; Yan, Y. Cooperative Tin Oxide Fullerene Electron Selective Layers for High-Performance Planar Perovskite Solar Cells. J. Mater. Chem. A 2016, 4, 14276-14283.

(14) Yang, M.; Zhou, Y.; Zeng, Y.; Jiang, C.-S.; Padture, N. P.; Zhu, K. Square-Centimeter Solution-Processed Planar $\mathrm{CH}_{3} \mathrm{NH}_{3} \mathrm{PbI}_{3}$ Perovskite Solar Cells with Efficiency Exceeding 15\%. Adv. Mater. 2015, $27,6363-6370$.

(15) Rao, H.-S.; Chen, B.-X.; Li, W.-G.; Xu, Y.-F.; Chen, H.-Y.; Kuang, D.-B.; Su, C.-Y. Improving the Extraction of Photogenerated Electrons with $\mathrm{SnO}_{2}$ Nanocolloids for Efficient Planar Perovskite Solar Cells. Adv. Funct. Mater. 2015, 25, 7200-7207.

(16) Yang, M.; Kim, D. H.; Klein, T. R.; Li, Z.; Reese, M. O.; Tremolet de Villers, B. J.; Berry, J. J.; van Hest, M. F. A. M.; Zhu, K. Highly Efficient Perovskite Solar Modules by Scalable Fabrication and Interconnection Optimization. ACS Energy Letters 2018, 3, 322-328. 